\title{
Optimization of left ventricular ejection fraction measurement by two-dimensional echocardiography in patients with repaired tetralogy of Fallot: comparison of geometric methods with cardiovascular magnetic resonance
}

\author{
Jimmy C Lu*, Gregory J Ensing, Sunkyung Yu, Thor Thorsson, Janet E Donohue, Adam L Dorfman
}

From 15th Annual SCMR Scientific Sessions

Orlando, FL, USA. 2-5 February 2012

\section{Background}

In patients with repaired tetralogy of Fallot (rTOF), left ventricular ejection fraction (LVEF) predicts adverse clinical outcomes. Cardiovascular magnetic resonance (CMR) is the gold standard for LVEF measurement, but two-dimensional echocardiography (2DE) is commonly used for serial evaluation of LVEF. The optimal 2DE method for LVEF measurement and limiting factors in this population are not known.

\section{Methods}

This single-center retrospective study included all patients with rTOF with CMR performed 2007-2010 without general anesthesia and 2DE within 3 months of CMR, with adequate images for analysis by all 2DE methods. Two investigators blinded to CMR results measured LVEF from 2DE studies by biplane Simpson's (BiS) method (using apical 4-chamber and apical or parasternal 3-chamber images), 5/6 area*length (AL), and visual estimate. Two investigators blinded to $2 \mathrm{DE}$ results measured LVEF from CMR by Simpson's method, as well as by AL, to test validity of geometric assumptions. An investigator re-evaluated each modality at least one month later.

\section{Results}

In 20 patients ( $28.5 \pm 14.7$ years old, $40 \%$ female), visual estimation by $2 \mathrm{DE}$ best approximated LVEF by CMR

\footnotetext{
Pediatrics and Communicable Diseases, Division of Pediatric Cardiology, University of Michigan, Ann Arbor, MI, USA
}

(table), but with high interobserver variability (median 14.8\%). LVEF by AL correlated moderately with CMR, but with higher intraobserver (median $7.1 \%$ vs. $2.9 \%$, $\mathrm{p}=0.004$ ) and interobserver variability (median $11.1 \%$ vs. $3.8 \%, \mathrm{p}=0.004$ ) than CMR; LVEF by BiS correlated poorly with CMR. AL method on CMR closely agreed with Simpson's method on CMR. Relative to CMR, 2DE underestimated both short-axis area (diastolic 19.6 \pm 6.0 vs. $25.2 \pm 6.9 \mathrm{~cm} 2, \mathrm{p}=0.01$; systolic $9.8 \pm 3.4$ vs. $13.3 \pm 4.9$ $\mathrm{cm} 2, \mathrm{p}=0.01$ ) and LV length (diastolic $7.4 \pm 0.7$ vs. 8.8 $\pm 1.0 \mathrm{~cm}, \mathrm{p}<0.0001$; systolic $6.3 \pm 0.9$ vs. $7.5 \pm 1.0 \mathrm{~cm}$, $\mathrm{p}=0.0001$ ). AL method did not improve with use of 3chamber length. Substituting CMR short-axis area improved correlation $(\mathrm{r}=0.80, \mathrm{p}<0.0001)$ more than substituting CMR LV length $(\mathrm{r}=0.70, \mathrm{p}=0.001)$. Intraobserver and interobserver variability of $2 \mathrm{DE}$ systolic shortaxis area were higher in systole (median $12.7 \%$ and $15.4 \%$ ) than in diastole (median $4.0 \%$ and $10.2 \%$ ).

\section{Conclusions}

In adults with rTOF, AL method better correlates with CMR than BiS, but with high intra- and interobserver variability for all 2DE methods. Lack of agreement is affected predominantly by 2DE-derived areas, particularly systolic, rather than ventricular length or geometric assumptions. Strategies to optimize image position and border detection are most likely to improve 2DE performance in this population.

\section{Funding}

None. 
Table 1 Correlation and agreement of 2DE methods with CMR

\begin{tabular}{cccc}
\hline Method & Mean LVEF (SD) & Correlation & Mean difference (limits of agreement) \\
\hline CMR (Simpson's) & $53.3(7.2)$ & - & - \\
CMR AL & $55.7(8.9)$ & $r=0.90, p<0.0001$ & $-2.5(-10.1$ to 5.2$)$ \\
2DE visual estimate & $56.8(10.0)$ & $r=0.69, \mathrm{p}=0.001$ & $-3.5(-17.8$ to 10.8$)$ \\
2DE AL & $57.6(8.1)$ & $\mathrm{r}=0.59, \mathrm{p}=0.01$ & $-4.3(-18.1$ to 9.4$)$ \\
2DE BiS & $57.9(9.5)$ & $\mathrm{r}=0.35, \mathrm{p}=0.13$ & $-4.6(-23.7$ to 14.4$)$ \\
\hline
\end{tabular}

Published: 1 February 2012

doi:10.1186/1532-429X-14-S1-P108

Cite this article as: Lu et al:: Optimization of left ventricular ejection

fraction measurement by two-dimensional echocardiography in

patients with repaired tetralogy of Fallot: comparison of geometric

methods with cardiovascular magnetic resonance. Journal of

Cardiovascular Magnetic Resonance 2012 14(Suppl 1):P108.

Submit your next manuscript to BioMed Central and take full advantage of:

- Convenient online submission

- Thorough peer review

- No space constraints or color figure charges

- Immediate publication on acceptance

- Inclusion in PubMed, CAS, Scopus and Google Scholar

- Research which is freely available for redistribution

Submit your manuscript at www.biomedcentral.com/submit 